\title{
O enigma do número dois: os limites da tira em ambientes digitais
}

\section{Ramos, Paulo}

Resumen:

Las historietas brasileñas creadas para ambientes digitales han puesto a prueba los límites de esa forma de producción de cómics. Hay casos en que el formato de la historia deshace de los moldes tradicionales adoptados por los soportes impresos. Estos nuevos usos han fomentado una constatación y un cuestionamiento. La constatación: las tiras brasileñas contemporáneas han presentado una maleabilidad en el formato de las historias. El cuestionamiento: ¿cómo pueden ser consideradas historietas? La respuesta a esta pregunta es el objetivo central de este artículo, que trabajará específicamente con tiras de la serie Um Sábado Qualquer, de Carlos Ruas. Los trabajos del autor ayudarán a ejemplificar el tema, así

Cuadernos del Centro de Estudios de Diseño y Comunicación №74

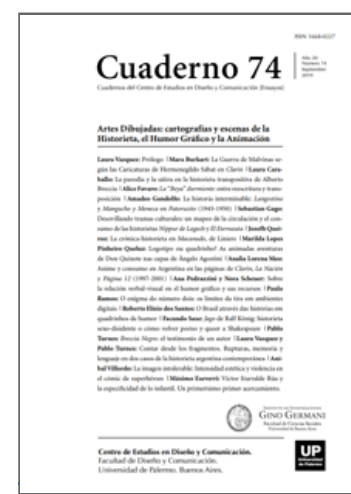

ISSN: 1668-0227

Artes Dibujadas:

cartografías y

escenas de la

Historieta, el Humor

Gráfico y la

Animación

Año XX, Septiembre 2019, Buenos

Aires, Argentina | 256 páginas

descargar PDF ver índice de la publicación

Ver todos los libros de la publicación

compartir en Facebook

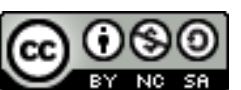

Esta obra está bajo una Licencia Creative Commons Atribución-NoComercialCompartirlgual 4.0 Internacional

como a orientar la exposición sobre el tema.

Palabras clave: Historietas - soporte - entornos digitales.

( $^{*}$ Jornalista e professor do Departamento de Letras da Universidade Federal de São Paulo, Brasil, onde coordena o Grupo de Pesquisa sobre Quadrinhos (Grupesq). Integra o Observatório de Histórias em Quadrinhos da Universidade de São Paulo. É autor de várias obras e artigos sobre quadrinhos.

Definindo o problema

Mais do que humor, parte das tiras cômicas brasileiras contemporâneas tem trazido também alguns enigmas. Com formas variadas e inovadoras, distantes das tradicionais, elas chegam a pôr à prova o que se entende por 
essa forma de produção de histórias em quadrinhos. É algo que fica mais evidente nos ambientes digitais, como o exemplo a seguir ajuda a ilustrar com precisão. (Ver Figura 1)

A história em quadrinhos faz parte da série Um Sábado Qualquer, do desenhista brasileiro Carlos Ruas. Construída em um formato semelhante ao do número dois, ela mostra os protagonistas -Deus, de barba, e Adão- sendo vitimados por um momento "inspirado" do autor.

A tal inspiração do desenhista foi criar uma narrativa que rompia com o padrão convencionado do que seria uma tira, como evidenciam as falas do personagem Adão, presentes no segundo e no terceiro quadrinhos (“Querendo romper paradigmas!"; “E resolveu fazer uma tira despadronizando o comum!"). Por conta do formato diferenciado, a dupla cai até chegar à parte debaixo, no que seria equivalente à base do número dois. "Eu odeio quanto ele inventa essas coisas!", completa Deus.

O autor já antecipava no título, "Pra Variar", a intenção de construir uma história fora do padrão. A expressão sugeria que, em vez de tiras pensadas para o tamanho tradicional, tendencialmente retangular e horizontal, haveria variação no molde usado para encapsular a narrativa. O que merece registro é que, apesar da forma diferenciada, a história continuou sendo rotulada como sendo uma tira.

Alguns dos leitores daquela produção também sinalizaram enxergar nela uma tira. Dos 14 comentários registrados naquela postagem1, dois se referiam à narrativa como sendo uma tira ou tirinha (forma sinônima, bastante corrente no Brasil). Houve também observações dos leitores sobre o formato utilizado. Dois comentários reconheceram naquele molde o contorno de um número dois e brincaram com hipóteses sobre os motivos da escolha do formato (mantivemos os trechos com a mesma grafia que aparecia no site):

- "O post tem formato de 2, indica que foi postado a 22 horas. Estou postando as 11:20.. $1+1: 20$. Tenho 2 calopsita com 2 olhos cada. Uma conspiração iluminatti. Abram seus óleos."

- "O post tem formato de 2. A tirinha é a n 1342. Temos $1+3+4+2=10.10$ é 2 em binário. Resolvido o mistério. Viajei longe nessa kkkkk"

Interessam menos as hipóteses mirabolantes, redigidas em tom claramente cômico, e mais as constatações reais de que a história se valeu de um formato diferente do usual e que, mesmo assim, continuou sendo rotulada como tira pelo autor e lida desse modo pelos leitores. Fica mais claro, agora, o teor do enigma mencionado anteriormente: esse caso configuraria, de fato, uma tira? Refazendo a pergunta de outra maneira: uma tira pode contemporaneamente apresentar um formato narrativo tão maleável como esse?

A resposta a essas questões é o objetivo principal deste artigo. $O$ foco da discussão serão tiras brasileiras, em particular as que circulam nos ambientes digitais. O fio-condutor da exposição é a leitura de que mudanças no formato das tiras não são uma exclusividade de sites, blogs e redes sociais -isso já ocorria no século passado nos suportes em papel-, mas é algo que encontrou novas possibilidades com o surgimento da internet. A questão central é se elas continuariam sendo tiras em situações-limite, como a vista na narrativa criada por Carlos Ruas. 
$\mathrm{Na}$ literatura sobre as histórias em quadrinhos, encontram-se tanto defensores de que o surgimento delas tenha ocorrido nos Estados Unidos nos anos finais do século 19 quanto quem postule que já havia exemplos anteriores em outros países2. Embora divergentes, essas duas correntes de pensamento parecem concordar que a criação das tiras, nos moldes como passaram a ser conhecidas, tenha ocorrido mesmo na indústria jornalística norte- -americana.

Observando exemplos da época, publicados nos jornais estadunidenses da virada do sé- culo 19 para o 20, fica claro que não existia ainda um formato padrão estabelecido. O que havia eram formatos, no plural mesmo, dos mais variados3 . O mérito da imprensa norte- -americana foi o de padronizar essas diferentes experiências, dando a elas regularidade e uma cara própria. Esse movimento editorial começou a ganhar corpo no fim do século 19, com o surgimento dos suplementos com narrativas ilustradas.

Com circulação aos domingos, esses cadernos dos jornais traziam conteúdos que até então não tinham um nome bem definido. Os títulos utilizados para os suplementos dialogavam com palavras relacionadas ao teor humorístico das histórias: funnies, humor, comics. Nos anos e décadas seguintes, este último termo se impôs em relação aos demais e se tornou sinônimo de quadrinhos naquele país.

Esses suplementos dominicais tinham uma tabula rasa a ser preenchida. No caso dos formatos, o limite eram as dimensões físicas do jornal. Fora isso, como dito, havia quase tudo: histórias do tamanho de uma página, outras um pouco menores, algumas com o que seria equivalente a uma, duas ou três tiras, umas mais horizontais, outras mais verticais, parte delas quadrada.

Nos anos inaugurais do século 20, a concentração dessas histórias ocorreu nos suplementos de quadrinhos que circulavam aos domingos. Ao longo da semana, havia um vácuo de produções assim nos jornais dos Estados Unidos. Um início de mudança desse cenário ocorreu no fim de 1907. Foi quando começou a ser impressa no San Francisco Chronicle uma narrativa que se diferenciava das demais por ser diária, e não semanal4 .

A história em questão se chamou inicialmente A. Mutt e foi criada por Bud Fisher. A proposta do desenhista era aproveitar a temática das corridas de cavalos. O personagem- -título seria mostrado apostando em um dos animais do páreo. Se Mutt acertaria ou não na escolha, isso só seria revelado na tira do dia seguinte, uma forma de fisgar a atenção do leitor para o próximo número do jornal.

A ideia de Fisher não era original. Algo bem parecido havia sido feito em outro jornal do país entre o final de 1903 e meados do ano seguinte. A série anterior tinha o título A. Piker Clerk e havia sido desenvolvida por Clare Briggs. Apesar das semelhanças, inclusive no título e na caracterização física dos personagens (Ver Figuras 2 e 3), havia uma diferença, que é o que de fato interessa para esta discussão: não se tratava de uma publicação diária, como ocorreu com A. Mutt.

A repercussão do trabalho de Bud Fisher foi grande e rápida. Antes mesmo do final de 1907, seus quadrinhos já trocavam de jornal, migrando para o concorrente, o San Francisco Examiner. Com a mudança, o desenhista procurou abordar outros temas, mais amplos que as corridas regionais de cavalos. O protagonista ganhou, então, um parceiro, o baixinho Jeff. Os nomes dos dois passaram a servir de título para a série -Mutt \& Jeff foram publicados até 1983. 
A inclusão de um parceiro para Mutt não foi a única mudança. Houve outra, bem mais significativa para a crescente e ávida indústria dos quadrinhos nos Estados Unidos. Percebeu-se que a mesma história poderia ser distribuída para mais de um jornal. Bastaria que se padronizasse aquele formato para que os outros diários também pudessem publicar o produto. Essa lógica, na prática, permitia que se ganhasse mais (muito mais) pelo mesmo serviço. Estava criado o sistema de fornecimento de tiras diárias, que anos depois seria exportado para outros países, inclusive o Brasil.

Pode-se dizer que esse modelo de produção ainda é o que predomina nos jornais, bem como o formato retangular e horizontal. No caso do Brasil, Ramos (2014) defende que tenham ocorrido também alguns pontos de fuga desse modelo padronizado das histórias. Isso seria percebido tanto nos suportes impressos, como os diários jornalísticos, as revistas e os livros, quanto no meio digital.

No caso dos jornais, os periódicos brasileiros passaram a dividir o espaço dedicado às tiras tradicionais -a maioria- com outros, maiores, equivalentes ao tamanho de duas delas. Houve também casos esporádicos de histórias impressas na vertical, e não na horizontal. Esse recurso podia ser visto também nas revistas infantis, que tendiam a encerrar a publicação com uma narrativa publicada dessa forma.

Menos frequente nos jornais, o formato quadrado se tornou um recurso bastante proveitoso para tiras de jornal que eram adaptadas para o suporte livro. Em vez de a história ser apresentada na horizontal, ela era dividida ao meio para que se adaptasse à página onde seria impressa. Dessa forma, um bloco de quadrinhos ficaria na parte de cima, o outro, na debaixo.

Sabe-se que esse recurso já ocorria desde pelo menos o final da década de 1910 nos Estados Unidos. Há exemplos de obras da série Bringing Up Father, de George McManus, que se valiam do recurso5. Além do realinhamento para o formato quadrado, encontram-se também outras possibilidades de rearranjo dos quadrinhos das tiras, a depender do tamanho do suporte em papel utilizado e do projeto editorial envolvido.

Apesar de existirem tais pontos de fuga do formato estabelecido, os suportes impressos tendem a manter certa regularidade na escolha do tamanho das tiras, seja ele qual for (retangular e horizontal, equivalente ao de duas tiras, quadrado). Algo oposto ao que se percebe na internet, tão marcada pela irregularidade dos moldes narrativos das tiras.

\section{Formatos flexíveis}

Em um jornal, o autor sabe exatamente o tamanho que tem para produzir a tira. Ele tende a ser fixo, sempre com as mesmas dimensões. Nos ambientes digitais, essas amarras impostas pelos suportes impressos se soltam e o desenhista ganha a liberdade de produzir a história no tamanho que julgar conveniente.

Na leitura de Ramos (2014), houve uma tendência inicial no Brasil de os quadrinistas reproduzirem na tela os formatos herdados do impresso. No caso das tiras, o recorrente era a produção da história no tamanho retangular e horizontal. Com o passar dos anos e com a percepção de que os suportes e mídias digitais permitiam novas experimentações, começaram a surgir outros moldes narrativos. Segundo sintetiza o pesquisador (Ramos, 2014, p. 101): 
Parece haver neste século 21 sinais do mesmo experimentalismo presenciado um século antes. A internet, sem dúvida, tem contribuído muito nesse sentido, embora haja ainda registros dos formatos convencionais da tira nos sites e blogs brasileiros. Mesmo assim, já existem casos suficientes, tanto nos meios impressos como virtuais, para autorizar uma definição que encampe um alargamento na dimensão física da tira.

Mais do que um alargamento, pode-se dizer também que haja uma flexibilização na regularidade de apresentação desses formatos. Se em um dia o autor opta por criar a tira no tamanho retangular e horizontal, nada impede que, no outro, apresente uma história em um molde completamente diferente.

Vejamos o caso do site Um Sábado Qualquer, de Carlos Ruas, série que rapidamente se tornou uma das tiras cômicas mais populares da internet brasileira6 e que tem norteado esta nossa discussão. Castro (2016) fez um levantamento detalhado das histórias veiculadas na página do autor, desde que ela foi iniciada em 26 de novembro de 2008 , como blog, até 2015 . O estudo somou 1.500 tiras.

A constatação do pesquisador é que a série tendia a apresentar inicialmente o formato tradicional de tiras usado nos jornais, ou seja, retangular e horizontal. Com o tempo, Ruas passou a flexibilizar o formato, optando por tamanhos maiores. A medição de Castro foi feita por meio do número de quadrinhos utilizados para a construção da história. Observemos os dados:

Na leitura de Castro (2016), haveria uma tendência de o desenhista utilizar uma forma prototípica de tira. No caso, seria a pensada no formato retangular e horizontal, composto por três quadros (maioria das ocorrências registradas, 27,61\%). A ele seriam mesclados outros moldes, a depender do que se pretendia narrar. Percebese um alto volume de histórias criadas com seis $(20,92 \%)$ ou mais quadrinhos $(18,49 \%)$, o que implica no uso de um tamanho maior que o convencional para a construção da narrativa. $O$ caso da imagem 1 se enquadraria nessa situação de narrativa maior, com mais quadrinhos (ela foi criada com nove quadros). Os exemplos a seguir ajudarão a entender melhor esses usos diferenciados. (Ver Figuras 4, 5 y 6)

As três histórias abordam o personagem Deus em diferentes momentos, pensando o processo de criação dos seres humanos. A proposta do autor é extrair humor dessa situação. Além da temática, as narrativas têm outro ponto comum: apesar dos formatos diferentes (retangular e horizontal, equivalente ao de duas tiras, longo), todas foram rotuladas como sendo tirinhas no site da série. Cria-se, assim, um contrato ficcional entre desenhista e leitor de que aquele conteúdo pode ser lido como tira, independentemente do tamanho apresentado.

Nesse contexto, em que predomina a maleabilidade dos formatos utilizados para a construção das histórias, o visitante da página virtual já estaria de certa forma preparado para ter contato com o exemplo que abre este capítulo, o da narrativa criada em molde semelhante ao do número dois. Embora reconheça ser algo diferente, aspecto evidenciado pelo próprio autor, o leitor aceita que se trate de uma tira, pelo que se observou nos registros deixados no espaço dos comentários daquela postagem.

O que se percebe é que a série não se pauta pela regularidade no tamanho das tiras. Por mais que possa predominar um modelo protípico, como o visto na Figura 4, o autor evidencia preferir a liberdade na construção de suas histórias. Algo que só é possível por conta da circulação em plataformas digitais -no impresso, por conta dos formatos fixos, isso seria algo impensável. 
Não se pode dizer que seja uma regra a variação de formatos. Mas também não se pode afirmar que se trate de um caso isolado no Brasil. O levantamento feito por Castro (2016) observou ainda outras duas séries digitais produzidas no país, Will Tirando, de Will Leite, e Vida de Suporte, de Andre Farias. Em ambas, ele identificou mudanças no molde das narrativas.

Castro analisou 1.240 tiras de Will Tirando e identificou predomínio de histórias com três quadros (25,16\%). Tiras com seis quadrinhos $(6,21 \%)$ ou com mais de seis $(12,5 \%)$ foram minoria, porém se fizeram presentes. Com Vida de Suporte, a maioria das 1.200 tiras foi composta por quatro quadros (56,75\%), mas houve registros de histórias maiores (16,17\% com seis quadrinhos e $9,58 \%$ com mais de seis).

Vê-se, portanto, que a flutuação dos formatos das tiras já é uma realidade na internet brasileira. Alguns deles chegam, inclusive, a pôr em discussão se aquele conteúdo seria, de fato, uma tira ou algo diferente, como é o caso da história de Carlos Ruas mostrada no início desta discussão.

\section{Obtendo respostas}

Não são todos os desenhistas de tiras que modificam tanto os formatos. No Brasil, há os que preferem o molde tradicional, há os que optam por outros com regularidade, há os que se assemelham ao que Carlos Ruas faz. De todo modo, constata-se que existe uma liberdade nos ambientes digitais sobre o tamanho que a narrativa terá. O que já implica na necessidade de se repensar as definições de tira e de suas dimensões, ora mais curtas, ora mais longas.

Para além disso, percebe-se também que essas dimensões, em dadas situações, põem à prova a própria percepção do que seja uma tira ou uma história em quadrinhos, como no exemplo que reproduzimos no início deste artigo. Construída em forma de número dois, aquela história foi rotulada pelo autor e aceita pelo leitor como sendo uma tira. Questionávamos, no início desta exposição, se tratava mesmo de uma tira. Diante do exposto, entendemos que sim. Seria mais um exemplo da maleabilidade que ela pode ter por conta da circulação em ambientes digitais.

Parece que a regra em sites, blogs e redes sociais é não ter regra. Pode-se utilizar tanto os formatos tradicionais da tira quanto outros, maiores, e até mesmo inusitados como o do número dois. Testemunha-se neste século 21 momento de experimentação semelhante ao vivido pelos desenhistas norte-americanos mais de cem anos antes, quando, por falta de um molde padrão, podiam flexibilizar o tamanho de suas histórias nos suplementos dos jornais. Uma diferença é que, antes, havia o limite da página. Agora não. O limite é a criatividade do desenhista.

Notas

1. Postagem é o nome dado a cada um dos conteúdos inseridos pelos autores nos blogs e nos sites que se assemelham aos blogs no modo de apresentação da página -ou seja, com a inserção do texto, de uma imagem e/ou de um vídeo, antecipado por um título e seguido de espaço para comentários dos internautas.

2. Há boa síntese sobre essas duas correntes em García (2010). 
3. Há farta seleção de histórias em quadrinhos do final do século 19 e início do 20 nos trabalhos de Blackbeard e Williams (1977), Baker e Brentano (2005) e Walker (2011).

4. A exposição sobre o surgimento das tiras de Bud Fisher foi baseado em exposição de Holtz (2007).

5. Há exemplo de tiras adaptadas em coletânea de Bringing Up Father datada de 1919 (Fisher, 1919).

6. É difícil medir com precisão o impacto de um site. Há, no entanto, alguns indicadores. Um deles é o número de seguidores que aquele conteúdo tem no Facebook. Em 6 de dezembro de 2016, a página de Um Sábado Qualquer computava 2.827.842 seguidores naquela rede social. Outro indicador são números do SimilarWeb, que ajuda a medir a audiência de sites e blogs. Na mesma data (6 de dezembro de 2016), a página de Carlos Ruas ocupava a posição 4.361 no ranking de sites brasileiros e 416 na área de artes e entretenimento. Um terceiro indicado é a tendência de a página e o autor serem lembrados como exemplos bem-sucedidos de criação de tiras na internet.

\section{Bibliografia}

Baker, N. \& Brentano, M. (2005). The World on Sunday: graphic art in Joseph Pulitzer's newspaper (1898-1911), New York, Time Warner Book Group.

Blackbeard, B. \& Williams, M. (1977). The Smithsonian colletction newspaper comics, Washington, Smithsonian Institution Press.

Castro, T. E. C. de (2016). Tiras cômicas online: mediação e interações na linguagem das tiras, 196 f., dissertação (Mestrado em Tecnologia), Curitiba, Universidade Tecnológica Federal do Paraná.

Fisher, B. (1919). Bringing Up Father: second series, New York, International Feature Service.

García, S. (2010). La novella gráfica. Bilbao: Astiberri.

Holtz, A. (2007). "Mutt, Jeff and Bud: the trio Who revolutionized comics", en Fisher, Bud, The Early Years of Mut \& Jeff, New York, NBM Publishing, p. 5-16.

Ramos, P. (2014). "Pontos de fuga: registros do processo de alargamento do formato das tiras", en Nona Arte: revista brasileira de pesquisas em histórias em quadrinhos, v. 3, n. 1, p. 85-103, disponible en: .

Walker, B. (2011). Comics: the complete collection, New York, Abrams ComicArt Books.

Abstract: Brazilian comic strips created for digital environments have put to the test the limits of what is meant by this form of comic book production. There are cases in which the format of the story disagrees with the traditional patterns adopted by printed media. These new uses have fostered a confirmation and a questioning. The confirmation: contemporary Brazilian comic strips have presented a malleability in the format of the stories. The questioning: cases like these can be considered strips? The answer to this question is the central goal of this article, which will specifically work with Carlos Ruas' Um Sábado Qualquer series. The author's works will help to exemplify the theme as well will guide the exposition on the subject. 
Key words: Comic strips - format - support - digital environments.

Resumo: Tiras brasileiras criadas para ambientes digitais têm posto à prova os limites do que se entende por essa forma de produção de história em quadrinhos. Há casos em que o formato da história destoa dos moldes tradicionais adotados pelos suportes impressos. Esses novos usos têm fomentado uma constatação e um questionamento. A constatação: tiras brasileiras contemporâneas têm apresentado uma maleabilidade no formato das histórias. O questionamento: casos como esses podem ser considerados tiras? A resposta a essa pergunta é o objetivo central deste artigo, que irá trabalhar especificamente com tiras da série Um Sábado Qualquer, de Carlos Ruas. Trabalhos do autor ajudarão a exemplificar o tema, bem como a nortear a exposição sobre 0 assunto.

Palavras chave: Tiras - formato - suporte - ambientes digitais.

[Las traducciones de los abstracts al inglés y portugués fueron supervisadas por el autor de cada artículo]

O enigma do número dois: os limites da tira em ambientes digitais fue publicado de la página 143 a página152 en Cuadernos del Centro de Estudios de Diseño y Comunicación №74 